it will find a place alongside conventional methods now in use when its indications, technicalities, and complications have been much more clearly defined, but it seems unlikely to supplant them for a long time yet.

\section{Total Replacement of the Knee}

Rheumatoid arthritis and osteoarthritis both commonly damage the knee, and neither can be halted reliably. Thus a painful, stiff, and often unstable knee is a frequent outcome. No surgical procedure can at present restore full painless movement and stability, but theoretically total excision of the joint and its replacement with a prosthesis could do this. The problem of the design and implantation of such prostheses is partly surgical, partly biomechanical.

Three prostheses are now in use in Great Britain-one designed by B. Walldius ${ }^{1}$ in Norway, and one by L. G. P. Shiers $^{2}$ and one by G. K. $\mathrm{McKee}^{3}$ in Britain. All in their present versions are cobalt-chrome hinges attached to stems introduced into the medullary cavities of the tibia and femur. Because they are to some extent under trial, and because their implantation has sometimes met with surgical difficulties, they have usually been employed for patients with advanced disease who are not expected to return to full activity. As might be expected of such patients, they do not regain full function of the knee, but pain is diminished and the knee may be moderately mobile for some years after the operation. It was impossible to be sure, though, on the basis of this experience, that these devices would withstand many years of relatively normal use.

To test prostheses rigorously in clinical practice would be both hazardous to the patient and time-consuming. Machines have therefore been developed in two laboratories in England which will simulate the mechanical environment of the hip and knee. In these conditions the working lifetime of a prosthesis can be shortened by continuous use, and its response can be studied as it wears out. At the Royal National Orthopaedic Hospital the biomechanics unit under J. T. Scales has developed a simulator in which particular attention has been paid to the hip. ${ }^{4}$ A second machine has been designed in the biomechanics unit of the Mechanical Engineering Department at Imperial College, London, and with this work has started on the knee.

Laboratory testing is quicker, safer, and-with respect to the mode of failure of the bearing itself-more informative than clinical testing, but it has the great disadvantage that the behaviour of soft tissues and changes in living bone cannot be simulated. Two design requirements for total-replacement prostheses lend themselves in particular to laboratory testing. These are, firstly, the biological acceptability and mechanical efficiency (i.e., the biomechanics) of the bearing, and, secondly, with certain reservations, the biomechanics of the bond between the bearing and bone.

1 Walldius, B., Acta orthop. scand., 1960, 30, 137

2 Shiers, L. G. P., f. Bone ft Surg., 1960, 42B, 31 .

- McKee, G. K., unpublished.

Scales, J. T., Duff-Barclay, I., and Burrows, H. J., Proceedings of a Symposium on Biomechanics and Related Bio-Engineering Topics, Charnle ed, Kenedi, R. M., p. 205. London.

- Goodman, L. S., and Gilman, A., The Pharmacological Basis of Therapeutrcs, 1965, 3rd ed., pp. 1030 and 1407. New York

' Leidholt, J. D., and Gorman, H A., f. Bone ft Surg., 1965, 47 A, 1414.
With regard to the bearing itself, only two combinations of material have so far proved to be acceptable experimentally and clinically - a cobalt-chrome alloy on itself ${ }^{1}$ and highdensity polyethylene on stainless steel..$^{5}$ At Imperial College $\underline{\underline{T}}$ bearings suitable for the knee will be tested in these two combinations, and other materials will be studied if both $\stackrel{\odot}{\varnothing}$

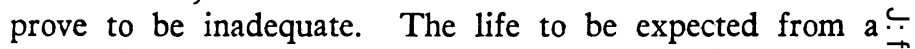
prosthetic knee constructed of either combination is unknown, $\underset{\overrightarrow{5}}{\overrightarrow{0}}$ but it is hoped that studies in the laboratory may afford a guide.

As the bearing wears out, friction rises, and particles and $\frac{\bar{\sigma}}{\frac{\sigma}{\sigma}}$ solutes are produced. Rising friction throws an increasing $\varrho$ load on to the bond between prosthesis and bone, and might be expected gradually to loosen the prosthesis. Thus measure- $\vec{\circ}$ ments of friction will provide a basis for preferring one design to another. Wear particles are deposited in the tissues $\vec{\omega}$ round cobalt-chrome prostheses and appear (in the short $\frac{\sigma}{\sigma}$ term) to be inert. Their long-term effect is unknown. Equally unknown (in relation to total-replacement prostheses) iv is the rate of production and biological effect of soluble salts $\mathrm{G}$ of chromium and cobalt. It is known, however, that these ions may be toxic. ${ }^{6}$ As to plastic materials, Teflon particles of are known to produce locally a very undesirable foreign-body 은 reaction. ${ }^{57}$ For these reasons it is planned to examine wear $\mathrm{N}$ particles and solutes produced in the laboratory, and this $v$ information will form another criterion of clinical acceptability.

At the hip a loose prosthesis is painful, and hence the bond $\overrightarrow{\mathscr{G}}$ between the prosthesis and bone is crucial to the success of the implant. The clinical success so far achieved at the hip has been attributed to the use of a quick-setting acrylic (polymethylmethacrylate) as a filling-agent between the prosthesis and the bone. ${ }^{8}$ The problem of bonding the prosthesis to bone is in some ways more difficult at the knee. This is $\underset{7}{\overrightarrow{1}}$ because, firstly, lateral and rotatory movements do not occur $\frac{0}{3}$ at the bearing (as they do in the hip), so that loads producing lateral bending and torsion must be borne entirely by the bond; and, secondly, the direction of the loads applied to the femoral component may vary through a right-angle (or more) when weight is taken on the flexed in contrast to the extended knee. Though so far satisfactory at the hip, it cannot therefore be assumed that polymethylmethacrylate will $\delta$ prove to be satisfactory in the long term at the knee. While a bond which is satisfactory in the laboratory may sub- 을 sequently fail clinically for biological reasons, laboratory $\mathrm{N}$ studies should eliminate mechanically unsuitable bonds.

it is to be hoped that further engineering and surgical study will make total replacement of the knee a more routine $\overline{0}$ surgical procedure. Combined engineering and surgical స్ట work of this kind will surely make a valuable contribution to medicine-perhaps especially to orthopaedics-in the 0 future.

\section{Public Health Dispute}

At a special meeting on 17 May (Supplement, p. 132) the B.M.A. Council decided that sanctions should be introduced at once on behalf of public health medical officers in their dispute with the Management Side of Whitley Committee C. This decision was taken after Council had heard an account of the previous day's emergency meeting of the Public Health 